\title{
Salivary Amylase Measurement
}

National Cancer Institute

\section{Source}

National Cancer Institute. Salivary Amylase Measurement. NCI Thesaurus. Code C98780.

The determination of the amount of salivary amylase present in a sample. 